\title{
Combined effects of tumor necrosis factor- $\alpha$ and interleukin-1 $\beta$ on lysyl oxidase and matrix metalloproteinase expression in human knee synovial fibroblasts in vitro
}

\author{
YANJUN ZHANG ${ }^{1,2}$, JIAHUAN JIANG $^{2}$, JING XIE $^{2}$, CHUNMING XU ${ }^{2}$, \\ CHUNLI WANG $^{2}$, LIN YIN ${ }^{2}$, LI YANG ${ }^{2}$ and KUO-LI PAUL SUNG ${ }^{2,3}$ \\ ${ }^{1}$ Department of Life Science, Hunan University of Science and Technology, Xiangtan, Hunan $411201 ;{ }^{2}$ Laboratory of \\ Biomechanics and Tissue Repair, Bioengineering College, Chongqing University, Chongqing 400044, P.R. China; \\ ${ }^{3}$ Departments of Bioengineering and Orthopedics, University of California, San Diego, CA 92093-0412, USA
}

Received January 17, 2016; Accepted January 13, 2017

DOI: $10.3892 / \mathrm{etm} .2017 .5264$

\begin{abstract}
Previous studies have demonstrated that inflammatory cytokines are associated with matrix metalloproteinases (MMPs) and/or lysyl oxidases (LOXs) produced by anterior cruciate ligament (ACL) fibroblasts, which may contribute to the poor healing ability of the ACL. To evaluate whether the synovium also participates in ACL healing, the inflammatory microenvironment of the knee joint cavity was mimicked following ACL injury, and the combined effects of tumor necrosis factor- $\alpha$ (TNF- $\alpha$ ) and interleukin- $1 \beta$ (IL-1 $\beta$ ) on the expression of MMPs and LOXs in synovial fibroblasts were studied. Cell viability was evaluated using trypan blue staining in the presence of TNF- $\alpha$ and IL- $1 \beta$, and the expression of LOXs and MMPs was measured by reverse transcription-quantitative polymerase chain reaction. MMP-2 activity was also measured by zymography. The results indicated that the combined effects of TNF- $\alpha$ and IL-1 $\beta$ inhibited LOX expression, while promoting MMP-1, -2 and -3 expression and MMP-2 activity in synovial fibroblasts. These changes may impede healing by altering the balance between the degradative and biosynthetic arms of the ligament tissue remodeling process. Collectively, the present results suggest that the poor healing ability of cruciate ligaments may be due to the sensitivity of the synovium to inflammatory factors. Therefore, the synovium potentially serves a key regulatory role in the joint cavity microenvironment and in the healing process of the ACL, and thus should be considered as a therapeutic target to aid in the treatment of patients with ACL trauma.
\end{abstract}

Correspondence to: Dr Kuo-Li Paul Sung, Laboratory of Biomechanics and Tissue Repair, Bioengineering College, Chongqing University, 174 Shazheng Road, Shapingba, Chongqing 400044, P.R. China

E-mail: klpsung@eng.ucsd.edu

Key words: lysyl oxidase, matrix metalloproteinase, tumor necrosis factor- $\alpha$, interleukin- $1 \beta$, synovial fibroblasts

\section{Introduction}

The increase in sporting activity over since 2000 in the USA has led to an increase in the incidence of knee joint injuries, with knee ligament injuries now the most prevalent sports injury (1). Injured anterior and posterior cruciate ligaments (ACL and PCL, respectively) heal poorly compared with medial and lateral collateral ligaments (MCL and LCL, respectively), and thus result in the onset of secondary complications, including meniscus tears, osteoarthritis and degenerative joint disease (2). In terms of treatment, cruciate ligament reconstitution through autografts, allografts and synthetic materials is considered to be the most effective treatment method, although difficulties remain in reproducing the biomechanics of ligaments following surgery $(3,4)$.

It has been demonstrated that the poor healing ability of cruciate ligaments may be due to a restricted vascular supply and limited vascular bed in the surrounding microenvironment (5). A number of previous studies suggest that the intrinsic cellular properties of the ACL and MCL, including proliferation, migration, extracellular matrix (ECM) synthesis and ECM remodeling, may be key contributors to the diminished healing potential of the ligaments (6-9). During tissue remodeling, older ECM molecules are subject to gradual degradation by proteolytic enzymes, while nascent ECM molecules undergo aggregation and cross-linking to form fibers (10). Normally, an equilibrium in the synthesis and degradation of ECM molecules exists and a disruption in this equilibrium may delay wound healing.

Matrix metalloproteinases (MMPs) are a family of zinc-dependent proteolytic enzymes that are involved in normal and pathological tissue remodeling processes, including tissue repair, embryonic development, rheumatoid arthritis and tumor invasion. This is through the proteolysis of selective ECM components, including collagens, elastin and glycoproteins $(11,12)$. Lysyl oxidases (LOXs) are a group of copper-dependent amine oxidases that initiate formation of the covalent cross-links between ECM proteins, thus providing the mechanical properties of the ECM, as well as proteinase resistance, including resistance to MMPs (13). Previous results have 
demonstrated that the presence of 0.1 Schiff-base cross-links per collagen molecule results in a 2-3-fold increase in resistance of the molecule to human collagenase, relative to non-cross-linked controls or samples $(14,15)$. Therefore, the balance between ECM synthesis and degradation during tissue remodeling is maintained by MMPs and LOXs.

During mechanical injury, a number of studies have documented differential expression of LOXs and MMPs in ACL fibroblasts relative to MCL fibroblasts, with ACL cells exhibiting decreased expression of LOXs and increased expression of MMPs. This may disrupt the equilibrium of the ECM remodeling process, potentially contributing to the differential healing abilities of the two ligaments $(9,16,17)$. Furthermore, in an in vivo rat model of ACL trauma, it was observed that articular tissues contributed to an elevation in MMP-2 in synovial fluids, thus inhibiting the remodeling process within injured cruciate ligaments. The synovium also exhibited a capacity to release MMP-2 into synovial fluids and convert inactive pro-MMP-2 into its active form among the articular tissues, thus indicating that synovium may be a key regulator of the joint cavity microenvironment following tissue injury within synovial joints (18). Furthermore, a previous mechanical compression study in vitro demonstrated that the differential expression and activity of MMP-2 in synovial fibroblasts may regulate the joint cavity microenvironment following articular tissue rupture (19). Similarly, a previous mechanical stretching study in vitro by our group demonstrated that during ligament remodeling, insufficient healing of cruciate ligaments is linked to an imbalance in the production of MMPs and LOXs in synovial fibroblasts, further indicating a regulatory effect of synovial fibroblasts on the joint cavity microenvironment (20).

Levels of the inflammatory cytokines tumor necrosis factor (TNF)- $\alpha$, interleukin (IL)-1 $\beta$ and IL- 6 are increased in knee joint fluid during the acute inflammatory phase of ACL trauma (21). These cytokines are considered to be important chemical mediators in the acute inflammatory phase of wound healing (22). Wang et al (19) observed that the regulatory activity of synovial fibroblasts regarding the joint cavity microenvironment was sensitive to inflammatory cytokines. In our previous mechanical stretching study, it was observed that TNF- $\alpha$ suppressed the expression of LOXs, while stimulating the expression and activity of MMPs in synovial fibroblasts, thus leading to a disruption in the ECM remodeling equilibrium and inhibition of articular tissue healing following trauma (20). Similar to TNF- $\alpha$, synovial fibroblasts may be sensitive to IL-1 $\beta$ in their regulation of the joint cavity microenvironment following articular tissue rupture (23). Therefore, the present in vitro study investigated the effects of IL- $1 \beta$ alone or in combination with TNF- $\alpha$ on the expression of LOXs and MMPs- $1,-2$ and -3 in human synovial fibroblasts, principally by evaluating the expression of LOXs and MMPs and the activity of MMP-2 by reverse transcription-quantitative polymerase chain reaction (RT-qPCR) and zymography, respectively, in the presence of IL-1 $\beta$ and TNF- $\alpha$.

\section{Materials and methods}

Cell culture. Human synovial fibroblasts were isolated from donor synovial tissues of four patients undergoing limb amputation (age range 30-60 years, mean $47.5 \pm 11.5$ years, two male and two female subjects) at the First Affiliated Hospital of Chongqing Medical University (Chongqing, China). These patients were enrolled in the study between September 2009 and March 2013. Donors with a pre-existing inflammatory reaction in the knee joint due to rheumatoid arthritis (RA), osteoarthritis (OA) or long-term knee joint pathological changes were excluded from the present study. The donor synovial tissue was obtained from patients following amputation surgery. The synovial tissues were immediately washed with 1x PBS with penicillin/streptomycin and cut into small $2 \mathrm{~mm}^{3}$ sections. Sections were suspended in high-glucose DMEM (Gibco; Thermo Fisher Scientific Inc., Waltham, MA, USA) supplemented with $10 \%$ fetal bovine serum (FBS; HyClone; Thermo Fisher Scientific Inc., Logan, UT, USA) and $100 \mathrm{U} / \mathrm{ml}$ penicillin/streptomycin and incubated at $37^{\circ} \mathrm{C}$ in a humidified atmosphere of $5 \% \mathrm{CO}_{2}$. After the fibroblasts had migrated out from small tissues and attached to the bottom, the tissues were transferred to another flask and the adherent cells were grown until confluent. Some of the cells were frozen in $10 \%$ dimethyl sulfoxide with FBS in liquid nitrogen until use. The remaining cells were cultured and maintained in 10\% FBS-DMEM at $37^{\circ} \mathrm{C}$ in a humidified atmosphere of $5 \% \mathrm{CO}_{2}$. Cells isolated from different donors were kept as separate samples. All experiments were carried out on cells from passages 1 to 5. Ethical approval from the Institutional Review Board (Chongqing University, Chongqing, China) was obtained prior to the study. All procedures were followed according to the ethical principles and protocols approved by Chongqing University and Chongqing Medical University. All patients provided informed consent for the use of their tissues in the study.

Cytokine treatment. For each experiment, fibroblasts of the control groups and the treatment groups were seeded at a density of $5 \times 10^{5}$ cells $/ 25 \mathrm{~cm}^{2}$ flask (Corning Incorporated, Corning, NY, USA). Cells were given $48 \mathrm{~h}$ to seed and equilibrate at $37^{\circ} \mathrm{C}$. Culture medium was then removed and replaced by $2 \%$ (FBS) HG-DMEM for a $16 \mathrm{~h}$ starvation period (a pilot study revealed that cells were more vulnerable to death in a FBS-free HG-DMEM). Medium was subsequently removed and replaced with $1 \%$ FBS HG-DMEM containing TNF- $\alpha$ $(1,5,10$ and $20 \mathrm{ng} / \mathrm{ml})$ or IL-1 $\beta(1,5,10$ and $20 \mathrm{ng} / \mathrm{ml}$ ) (both Peprotech, Rocky Hill, NJ, USA) and incubated at $37^{\circ} \mathrm{C}$ for $3 \mathrm{~h}$. Based on the results of these experiments, separate groups of fibroblasts were cultured for 1,2,3 and $6 \mathrm{~h}$ in the presence or absence (control cells) of $10 \mathrm{ng} / \mathrm{ml} \mathrm{TNF-} \alpha$ and/or $10 \mathrm{ng} / \mathrm{ml}$ IL-1 $\beta$. Total RNA samples were extracted at 1,2, 3 and $6 \mathrm{~h}$ and at $0 \mathrm{~h}$, as a control, prior to RT-qPCR. Conditioned medium was also collected after $12,24,48$, and $72 \mathrm{~h}$ of cell culture for zymography analysis of MMP-2 activity (23).

Cell viability assay. Cell viability was determined by the trypan blue dye exclusion test. A total of $2 \times 10^{5}$ cells/well were seeded in in 6-well plates with different concentrations of TNF- $\alpha(1,5,10$ and $20 \mathrm{ng} / \mathrm{ml})$ and IL-1 $\beta(1,5,10$ and $20 \mathrm{ng} / \mathrm{ml})$ for $24 \mathrm{~h}$ in a humidified incubator $\left(5 \% \mathrm{CO}_{2}\right.$ at $\left.37^{\circ} \mathrm{C}\right)$. Cells were trypsinized and resuspended in equal volumes of culture medium and trypan blue at $37^{\circ} \mathrm{C}$ for $3 \mathrm{~min}$. Viable (unstained) and nonviable (blue-stained) cells were counted using a Neubauer chamber (LO; Laboroptik GmbH, Bad Homburg, Germany) to calculate the total number of viable cells. 
Table I. Primer sequences used in reverse transcription-quantitative polymerase chain reaction.

\begin{tabular}{lll}
\hline Gene & \multicolumn{1}{c}{ Forward primer sequence (5'-3') } & \multicolumn{1}{c}{ Reverse primer sequence (5'-3') } \\
\hline GAPDH & GCACCGTCAAGGCTGAGAAC & TGGTGAAGACGCCAGTGGA \\
LOX & GCATACAGGGCAGATGTCAGA & TTGGCATCAAGCAGGTCATAG \\
LOXL-1 & TGCCACCAGCATTACCACAG & GAGGTTGCCGAAGTCACAGG \\
LOXL-2 & CTGCAAGTTCAATGCCGAGT & TCTCCACCAGCACCTCCACTC \\
LOXL-3 & CAACAGGAGGTTTGAACGCTAC & GCTGACATGGGTTTCTTGTAA \\
LOXL-4 & TTCACCCACTACGACCTCCTCA & CAGCAGCCTACAGTCACTCCCT \\
MMP-1 & GGCTGAAAGTGACTGGGAAACC & TGCTCTTGGCAAATCTGGCGTG \\
MMP-2 & ACCGGGATAAGAAGTATGGATT & GTCATCATCGTAGTTGGTTGTG \\
MMP-3 & GACAAAGGATACAACAGGGAC & TGAGTGAGTGATAGAGTGGG
\end{tabular}

LOX, lysyl oxidase; LOXL, LOX-like homolog; MMP, matrix metalloproteinase.

$R T-q P C R$. RT-qPCR was used to compare the levels of steady state mRNA expression for a number of genes in conditioned and control cultures of human knee synovial fibroblasts. Total RNA was isolated from synovial fibroblasts using an RNeasy Plus Mini kit (Qiagen GmbH, Hilden, Germany), according to the manufacturer's protocol. RNA samples were quantified using a Nanodrop ${ }^{\circledR}$ spectrophotometer at 230/260/280 nm (Bio-Rad Laboratories, Inc., Hercules, CA, USA) and stored at $-80^{\circ} \mathrm{C}$. RNA samples were then treated with DNase I (Fermentas; Thermo Fisher Scientific, Inc.). RT-qPCR was then performed as described previously (16). Briefly, $20 \mu \mathrm{l}$ cDNA was synthesized from $1 \mu \mathrm{g}$ total RNA using a RevertAid First Strand cDNA Synthesis kit (Fermentas; Thermo Fisher Scientific, Inc.), according to the manufacturer's protocol. qPCR was performed with a Quanti-Tect SYBR Green PCR kit (Qiagen $\mathrm{GmbH}$ ) using an iCycler iQ Real Time Detection System (Bio-Rad Laboratories, Inc.). The reaction was initiated by activating the polymerase with a 15 min pre-incubation at $95^{\circ} \mathrm{C}$ Amplification was achieved with 45 cycles of $15 \mathrm{sec}$ denaturation at $94^{\circ} \mathrm{C}, 20-30 \mathrm{sec}$ annealing at $65^{\circ} \mathrm{C}$ and $10 \mathrm{sec}$ extension at $72^{\circ} \mathrm{C}$. The program was concluded by a melting curve analysis. All experiments were performed in triplicates. The copy numbers of each gene were determined using the $2^{-\triangle \Delta C q}$ method (24). GAPDH was used as an internal control. The Basic Local Alignment Search Tool database (https://blast.ncbi.nlm.nih.gov/Blast.cgi) was used to verify gene specificity of all primer sequences. The primers used were for MMP-1, MMP-2, MMP-3, LOX, LOX- like homolog 1 (LOXL-1), LOXL-2, LOXL-3, LOXL-4 and GAPDH, as an internal control, and are presented in Table I.

Zymography. MMP-2 activity in culture media samples was assayed using a $0.05 \%$ gelatin zymography gel, as described previously (5). Briefly, $10 \mu 1$ of each sample was mixed with an equal amount of Laemmli sample buffer $(62.5 \mathrm{mM}$ Tris-hydrogen chloride, 25\% glycerol, $2 \%$ SDS and $0.01 \%$ bromophenol blue, $\mathrm{pH}$ 6.8) and separated on a $10 \%$ SDS-PAGE gel copolymerized with $0.05 \%$ gelatin. Enzyme activity was regained by removing the SDS, whereby gels were washed three times for $1.5 \mathrm{~h}$ in total in $2.5 \%$ Triton X-100 at room temperature following electrophoresis. Washed gels were then bathed in proteolysis buffer $(50 \mathrm{mM}$ calcium chloride, $0.5 \mathrm{M}$ sodium chloride and $50 \mathrm{mM}$ Tris, $\mathrm{pH}$ 7.8) and incubated at $37^{\circ} \mathrm{C}$ for $15 \mathrm{~h}$. Following incubation, gels were rinsed in a $2.5 \%$ Triton $\mathrm{X}-100$ solution and stained at room temperature with Coomassie blue (45\% methanol, $44.75 \% \mathrm{H}_{2} \mathrm{O}, 10 \%$ acetic acid and $0.25 \%$ Coomassie blue R-250) for $1 \mathrm{~h}$ on a rotator. Gels were then destained with a $40 \%$ methanol, $7.5 \%$ acetic acid and $52.5 \% \mathrm{H}_{2} \mathrm{O}$ solution until white bands were clearly visible against the Coomassie blue background. Bands were scanned with a densitometer (GS-800; Bio-Rad Laboratories, Inc.) and quantification was performed using Quantity One 4.6.3 software (Bio-Rad Laboratories, Inc.). The experiment was repeated three times, and the relative density values were subjected to statistical analysis.

Statistical analysis. Data are expressed as the mean \pm standard deviation. Data were statistically analyzed by one-way analysis of variance and a post hoc Fisher's LSD test. Statistical analysis was performed using a SPSS software, version 13.0 (SPSS, Inc., Chicago, IL, USA). P $<0.05$ was considered to indicate a statistically significant difference.

\section{Results}

Cell viability. No cytotoxic effects of the exogenous inflammatory factors TNF- $\alpha$ and IL-1 $\beta$ on human synovial fibroblasts were observed by Trypan blue staining (data not shown). Furthermore, cell viability did not significantly differ with increasing doses of TNF- $\alpha$ and IL- $1 \beta$.

TNF- $\alpha$ has differential effects on the expression of LOXs and MMPs in human knee synovial fibroblasts. RT-qPCR was used to evaluate the effects of TNF- $\alpha$ on the expression of LOX and MMP mRNA (Fig. 1A and B). It was observed that addition of TNF- $\alpha(0-20 \mathrm{ng} / \mathrm{ml})$ led to a decrease in LOX expression. The inhibitory effect of LOX and LOXL-3 by TNF- $\alpha$ was concentration-dependent. The inhibitory effect reached a maximum at $5 \mathrm{ng} / \mathrm{ml} \mathrm{TNF-a} \mathrm{for} \mathrm{LOXL-1.} \mathrm{The} \mathrm{expressions}$ of LOXL-2 and LOXL-4 reached a maximum at $5 \mathrm{ng} / \mathrm{ml}$ TNF- $\alpha$ and subsequently declined below the control values in response to increasing TNF- $\alpha$ concentration (Fig. 1A), while significantly increasing the level of MMP expression (MMP-1, MMP-2, MMP-3; Fig. 1B) in synovial fibroblasts, relative to 
A
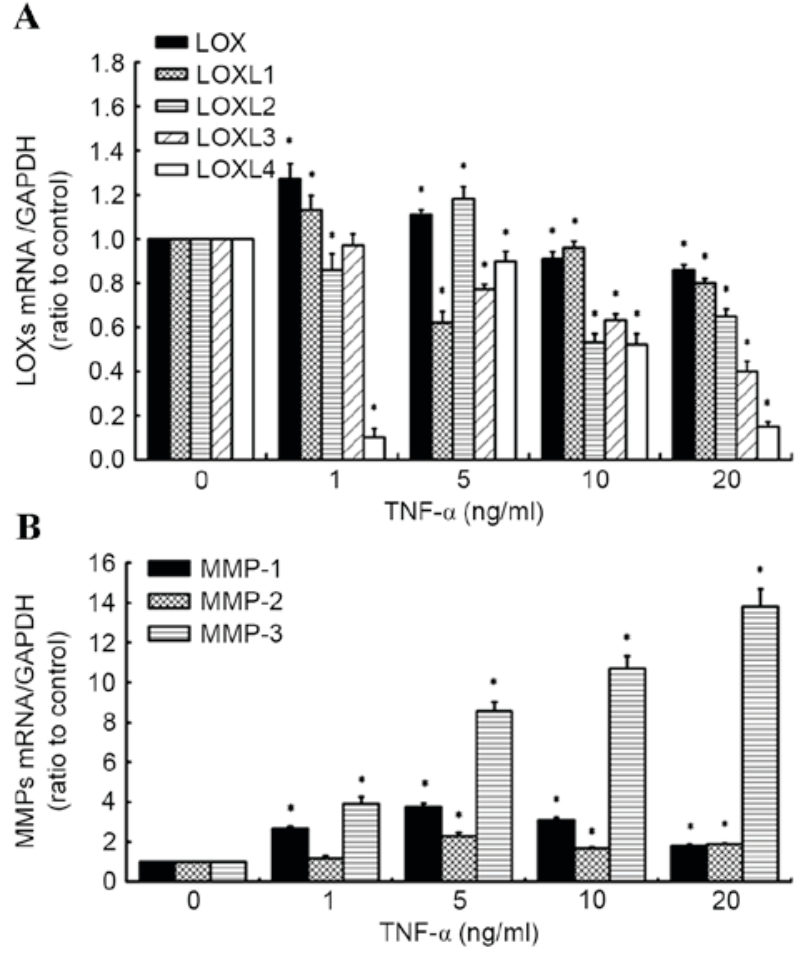

Figure 1. Effects of TNF- $\alpha$ on the expression of LOX and MMP family members in human knee synovial fibroblasts. Reverse transcription-quantitative polymerase chain reaction was used to evaluate the effects of TNF- $\alpha$ (0-20 ng/ml) on the levels of (A) LOX and (B) MMP family member mRNA levels. Data are presented as the mean \pm standard deviation, $\mathrm{n}=4$. ${ }^{*} \mathrm{P}<0.05$ vs. untreated control cells ( $0 \mathrm{ng} / \mathrm{ml} \mathrm{TNF-} \alpha$ ). TNF- $\alpha$, tumor necrosis factor- $\alpha$; LOX, lysyl oxidase; MMP, matrix metalloproteinase.

untreated control cells. These results are similar to those of our previous study into the effects of TNF- $\alpha$ (1 to $20 \mathrm{ng} / \mathrm{ml})$ on the expression of LOX and MMP family members (20).

$I L-1 \beta$ has differential effects on the expression of LOXs and MMPs in human knee synovial fibroblasts. RT-qPCR was also used to evaluate the effects of IL-1 $\beta$ on the expression of LOX and MMP mRNA (Fig. 2A and B). It was observed that all doses of IL-1 $\beta(1,5,10$ and $20 \mathrm{ng} / \mathrm{ml})$ significantly increased levels of LOX, LOXL-1 and -4 expression in synovial fibroblasts, relative to untreated control cells (all $\mathrm{P}<0.05$ ). Specifically, levels of LOXL-1 and -4 mRNA increased in a concentration-dependent manner between 5 and $20 \mathrm{ng} / \mathrm{ml}$ IL-1 $\beta$. By contrast, a significant increase in LOXL-2 and -3 expression at $1 \mathrm{ng} / \mathrm{ml}$ IL-1 $\beta$ (both $\mathrm{P}<0.05$ ) was followed by a significant decrease in LOXL-2 and -3 expression at $5 \mathrm{ng} / \mathrm{ml}$ IL-1 $\beta$ (both $\mathrm{P}<0.05$ ), relative to control cells. However, significant increases in LOXL-2 and -3 mRNA were observed in a concentration-dependent manner between 5 and $20 \mathrm{ng} / \mathrm{ml}$ IL-1 $\beta$, relative to control cells (both $\mathrm{P}<0.05$; Fig. $2 \mathrm{~A}$ ).

Analogous to the effects of TNF- $\alpha$, it was observed that all concentrations of IL-1 $\beta$ significantly increased the levels of MMP-1, 2 and 3 mRNA, relative to control cells (all $\mathrm{P}<0.05$; Fig. 2B). Specifically, maximum increases in MMP-1 and -3 mRNA were observed in cells treated with $5 \mathrm{ng} / \mathrm{ml}$ IL-1 $\beta$, relative to control cells (4.76- and 3.82-fold increases, respectively), while MMP-2 expression increased in a concentration-dependent manner, with a maximum 2.6-fold increase
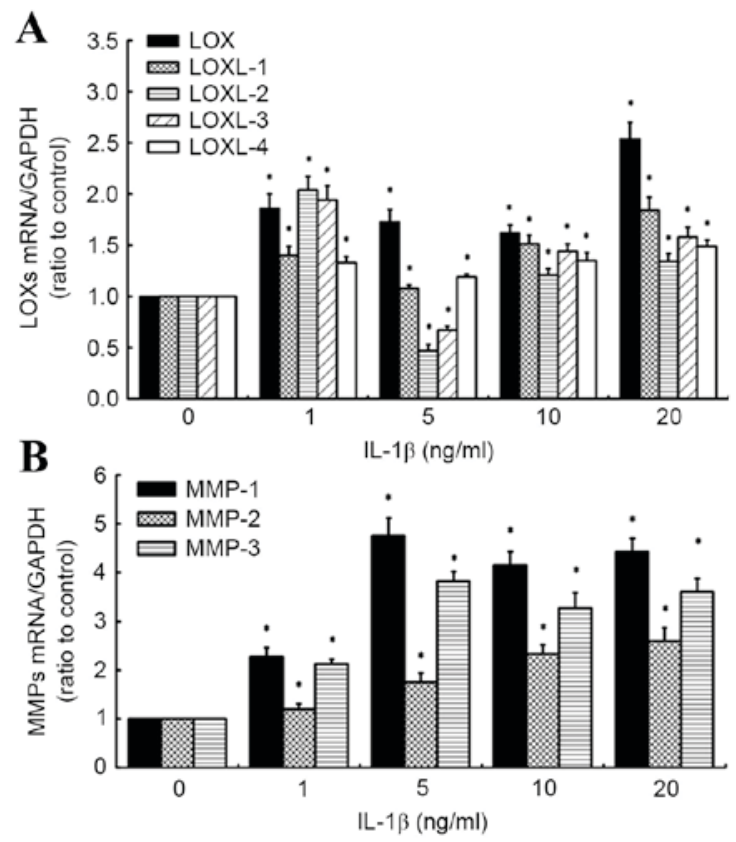

Figure 2. Effects of IL-1 $\beta$ on the expression of LOX and MMP family members in human knee synovial fibroblasts. Reverse transcription-quantitative polymerase chain reaction was used to evaluate the effects of IL-1 $(0-20 \mathrm{ng} / \mathrm{ml})$ on the levels of (A) LOX and (B) MMP family member mRNA. Data are presented as the mean \pm standard deviation, $n=4$. ${ }^{*} \mathrm{P}<0.05$ vs. untreated control cells $(0 \mathrm{ng} / \mathrm{ml}$ IL-1 $\beta)$. IL-1 $\beta$, interleukin- $1 \beta$; LOX, lysyl oxidase; MMP, matrix metalloproteinase.

observed at the highest IL-1 $\beta$ concentration $(20 \mathrm{ng} / \mathrm{ml})$. Based on these results, doses of $10 \mathrm{ng} / \mathrm{ml} \mathrm{TNF}-\alpha$ and $10 \mathrm{ng} / \mathrm{ml} \mathrm{IL-1 \beta}$ were used in further experiments.

A time course of TNF- $\alpha$ in combination with $I L-1 \beta$ alters the expression of LOXs in human knee synovial fibroblasts. RT-qPCR was performed on fibroblasts administered a time course of $10 \mathrm{ng} / \mathrm{ml} \mathrm{TNF-} \alpha$ and/or $10 \mathrm{ng} / \mathrm{ml} \mathrm{IL-1} \beta$ (for 1, 2, 3 and $6 \mathrm{~h}$ ) to determine the effects on the expression of LOXs (LOX, LOXL-1, -2, -3 and -4; Fig. 3A-D). Relative to control cells at corresponding time points, it was observed that levels of LOX mRNA in synovial fibroblasts treated with $10 \mathrm{ng} / \mathrm{ml}$ IL-1 $\beta$ significantly increased at all time points $(1,2,3$ and $6 \mathrm{~h}$; all $\mathrm{P}<0.05)$ in a time-dependent manner, reaching a maximum at $6 \mathrm{~h}$ post-treatment (Fig. 3A). By contrast, $10 \mathrm{ng} / \mathrm{ml} \mathrm{TNF}-\alpha$ significantly inhibited expression of LOX at all time points relative to control cells $(\mathrm{P}<0.05$; Fig. 3A). In fibroblasts treated with a combination of the inflammatory factors $(10 \mathrm{ng} / \mathrm{ml} \mathrm{TNF}-\alpha+$ $10 \mathrm{ng} / \mathrm{ml}$ IL-1 $\beta$ ), LOX expression was significantly inhibited at $1 \mathrm{~h}(\mathrm{P}<0.05)$ and $6 \mathrm{~h}(\mathrm{P}<0.05)$ post-cytokine treatment, all relative to control cells at the corresponding time points (Fig. 3A).

In addition, it was observed that LOXL-1 expression was significantly inhibited in synovial fibroblasts treated with $10 \mathrm{ng} / \mathrm{ml} \mathrm{TNF}-\alpha$ at all time points (all $\mathrm{P}<0.05$ ). LOXL-1 was also significantly inhibited by $10 \mathrm{ng} / \mathrm{ml} \mathrm{IL-1} \beta$ at $1 \mathrm{~h}$ post-treatment, relative to control cells $(\mathrm{P}<0.05)$; however was significantly increased at 2, 3 and $6 \mathrm{~h}$ post-treatment (all $\mathrm{P}<0.05$ ), reaching a maximum at $3 \mathrm{~h}$. In fibroblasts treated with a combination of the inflammatory factors, there was a significant inhibitory effect on LOXL-1 expression at all time points $(\mathrm{P}<0.05)$, with more marked inhibition of LOXL-1 observed 

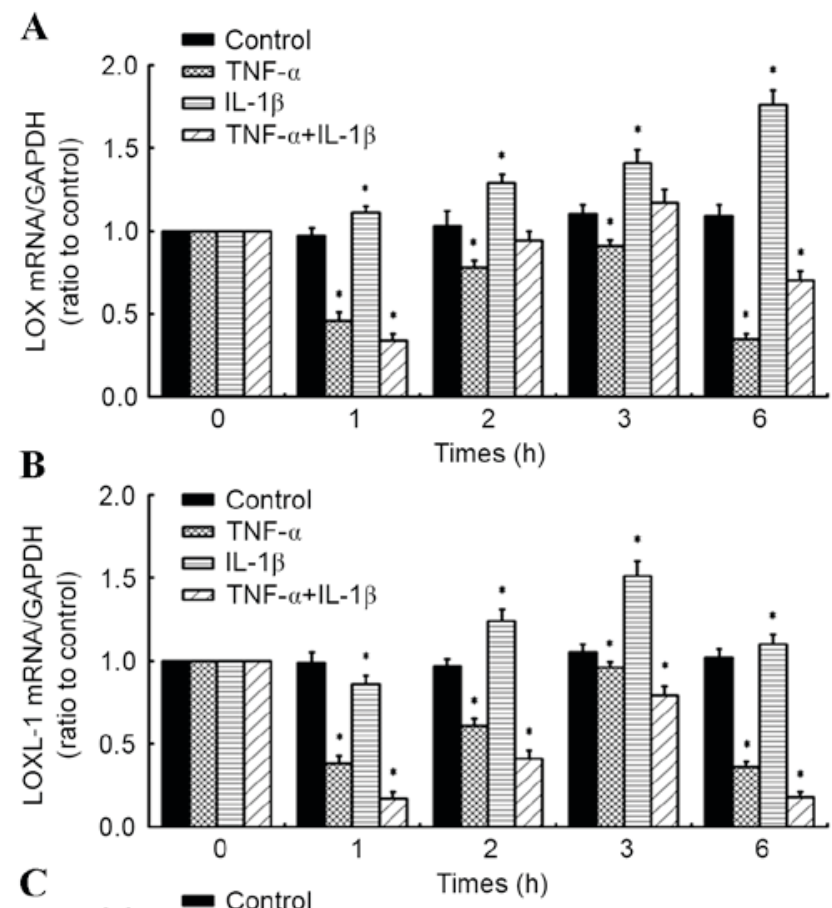

compared to that in cells treated with TNF- $\alpha$ or IL-1 $\beta$ alone, relative to their respective control cells (Fig. 3B).

At all time points, TNF- $\alpha$ inhibited the expression of LOXL-2 in synovial fibroblasts, relative to control cells at corresponding time points (all $\mathrm{P}<0.05$; Fig. 3C). By contrast, LOXL-2 was significantly upregulated following treatment with IL-1 $\beta$ for 1,2 and $3 \mathrm{~h}$, reaching a maximum at $2 \mathrm{~h}$ post-treatment, relative to control cells (all $\mathrm{P}<0.05$ ). However, LOXL-2 expression significantly decreased at $6 \mathrm{~h}$ post-treatment $(\mathrm{P}<0.05)$. In fibroblasts treated with a combination of the inflammatory factors, LOXL-2 expression significantly decreased at 1, 3 and $6 \mathrm{~h}$ post-treatment (all $\mathrm{P}<0.05$ ). However, LOXL-2 mRNA significantly increased at $2 \mathrm{~h}$ post-treatment $(\mathrm{P}<0.05)$, though this was less marked than for fibroblasts treated with IL-1 $\beta$ alone, relative to their respective control cells (Fig. 3C).

Furthermore, LOXL-3 expression was significantly inhibited in synovial fibroblasts treated with $10 \mathrm{ng} / \mathrm{ml} \mathrm{TNF}-\alpha$ at all time points (all $\mathrm{P}<0.05$; Fig. 3D). By contrast, exposure of synovial fibroblasts to $10 \mathrm{ng} / \mathrm{ml}$ IL-1 $\beta$ caused a significant increase in LOXL-3 expression at 2, 3 and $6 \mathrm{~h}$ post-treatment (each $\mathrm{P}<0.05)$, though significant downregulation in LOXL-3 mRNA was initially observed at $1 \mathrm{~h}$ post-treatment $(\mathrm{P}<0.05$; Fig. 3D). The combination of TNF- $\alpha$ plus IL- $1 \beta$ significantly inhibited LOXL-3 expression at all time points, relative to control cells at corresponding time points (Fig. 3D).

Analogous to LOX, LOXL-1, 2 and 3, LOXL-4 expression was significantly inhibited by $10 \mathrm{ng} / \mathrm{ml} \mathrm{TNF}-\alpha$ at all time points (all $\mathrm{P}<0.05$; Fig. 3E). Similarly, exposure of synovial fibroblasts to $10 \mathrm{ng} / \mathrm{ml}$ IL-1 $\beta$ caused a significant downregulation in LOXL-4 expression at 1, 2 and $6 \mathrm{~h}$ post-treatment (all $\mathrm{P}<0.05)$, though a significant upregulation in LOXL-4 mRNA was observed at $3 \mathrm{~h}$ post-treatment $(\mathrm{P}<0.05$; Fig. $3 \mathrm{E})$. In fibroblasts exposed to a combination of TNF- $\alpha$ and IL-1 $\beta$, a significant decrease in LOXL-4 expression was observed at all time points (all $\mathrm{P}<0.05$ ), with more marked inhibition of LOXL-4 observed compared to that in cells treated with IL-1 $\beta$ alone at 1,2 and $6 \mathrm{~h}$ post-treatment, relative to their respective control cells (Fig. 3E).

TNF- $\alpha$ in combination with IL-1 $\beta$ induces MMP-1, 2 and 3 expression in human knee synovial fibroblasts. RT-qPCR was also used to determine the effects of $10 \mathrm{ng} / \mathrm{ml} \mathrm{TNF-} \alpha$ and/or $10 \mathrm{ng} / \mathrm{ml}$ IL-1 $\beta$ on the expression of MMP-1, 2 and 3 in synovial fibroblasts (Fig. 4A-C). It was observed that MMP-1 mRNA was significantly upregulated by TNF- $\alpha$ or IL- $1 \beta$ treatment alone at all time points, relative to untreated control cells at corresponding time points (all $\mathrm{P}<0.05$; Fig. 4A). In addition, combined treatment with TNF- $\alpha$ and IL-1 $\beta$ caused a significant upregulation in MMP-1 expression at all time points (all $\mathrm{P}<0.05$ ), with more marked upregulation of MMP-1 observed compared to that in cells treated with TNF- $\alpha$ or IL-1 $\beta$ alone (Fig. 4A).

Individual treatment with TNF- $\alpha$ or IL-1 $\beta$ also caused a

Figure 3. Effects of inflammatory cytokine time course on LOX family member expression in human knee synovial fibroblasts. Reverse transcription-quantitative polymerase chain reaction was performed on fibroblasts administered a time course of $10 \mathrm{ng} / \mathrm{ml}$ TNF- $\alpha$ and/or $10 \mathrm{ng} / \mathrm{ml} \mathrm{IL-1 \beta}$ (for 1, 2, 3 and $6 \mathrm{~h}$ ) to determine the effects on the expression of (A) LOX, (B) LOXL-1, (C) LOXL-2, (D) LOXL-3 and (E) LOXL-4 expression. Data are presented as the mean \pm standard deviation, $n=4$. ${ }^{*} \mathrm{P}<0.05$ vs. untreated control cells at corresponding time points. TNF- $\alpha$, tumor necrosis factor- $\alpha$; IL-1 $\beta$, interleukin-1 $\beta$; LOX, lysyl oxidase; LOXL, LOX-like homolog 1. significant upregulation in MMP-2 expression in a time-dependent manner $(\mathrm{P}<0.05$; Fig. 4B). It was also observed that the combined treatment with TNF- $\alpha$ and IL- $1 \beta$ significantly increased MMP-2 expression at all time points (all $\mathrm{P}<0.05$ ), with more marked upregulation of MMP-2 observed compared to that in cells treated with TNF- $\alpha$ or IL-1 $\beta$ alone (Fig. 4B). 
A
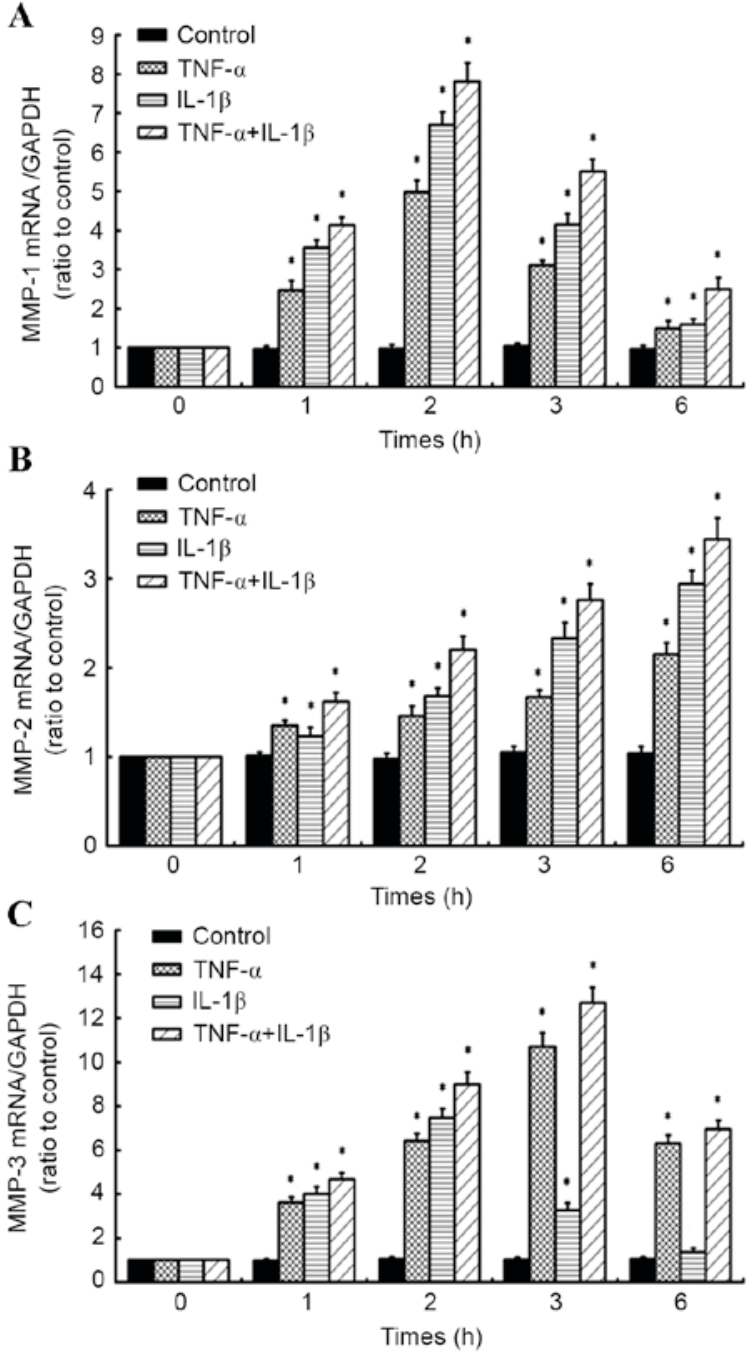

Figure 4. Effects of an inflammatory cytokine time course on MMP family member expression in human knee synovial fibroblasts. Reverse transcription-quantitative polymerase chain reaction was performed on fibroblasts administered a time course of $10 \mathrm{ng} / \mathrm{ml} \mathrm{TNF-} \alpha$ and/or $10 \mathrm{ng} / \mathrm{ml} \mathrm{IL-1 \beta}$ (for $1,2,3$ and $6 \mathrm{~h}$ ) to determine the effects on the expression of (A) MMP-1, (B) MMP-2 and (C) MMP-3. Data are presented as the mean \pm standard deviation, $n=4$. $^{*} \mathrm{P}<0.05$ vs. untreated control cells at corresponding time points. TNF- $\alpha$, tumor necrosis factor- $\alpha$; IL- $1 \beta$, interleukin- $1 \beta$; MMP, matrix metalloproteinase.

In fibroblasts exposed to TNF- $\alpha$ alone, significant upregulation of MMP-3 mRNA was observed at all times points (all $\mathrm{P}<0.05$ ), while individual IL-1 $\beta$ treatment induced significant upregulation of MMP-3 at 1, 2 and 3 h post-treatment (each $\mathrm{P}<0.05)$. This upregulation in MMP-3 peaked at 2 and $3 \mathrm{~h}$ in IL-1 $\beta$ - and TNF- $\alpha$-treated cells, respectively. The combined treatment of TNF- $\alpha$ and IL-1 $\beta$ also significantly increased MMP-3 expression at all time points (all $\mathrm{P}<0.05$ ), with more marked upregulation of MMP-3 observed compared to that of cells treated with TNF- $\alpha$ or IL-1 $\beta$ alone (Fig. 4C). Collectively, these data suggest that TNF- $\alpha$ and IL-1 $\beta$ have synergistic effects on the expression of MMPs.

TNF- $\alpha$ in combination with IL-1 $\beta$ induces MMP-2 expression and activity in human knee synovial fibroblasts. Gelatin zymography was used to determine the effects of TNF- $\alpha$ and/or IL-1 $\beta$ on the activity of MMP-2 in synovial fibroblasts by measuring the increase in band intensity for the active form of MMP-2 (62 kDa; Fig. 5A). Two forms (62 and $72 \mathrm{kDa}$ ) carry out the same enzymatic reaction; however, the $72 \mathrm{kDa}$ MMP-2 has $\sim 10 \%$ the activity of the $62 \mathrm{kDa}$ MMP-2 (9). It was observed that TNF- $\alpha$ or IL-1 $\beta$ treatment alone significantly stimulated the conversion of inactive pro-MMP-2 (72 kDa) into active MMP-2 (62 kDa) at all concentrations of each cytokine and when treated with a combination of both cytokines, in a time-dependent manner (Fig. 5B and C). Specifically, relative to control cells, synovial fibroblasts treated with 1, 10 and $20 \mathrm{ng} / \mathrm{ml}$ TNF- $\alpha$ for $72 \mathrm{~h}$ exhibited 1.32-, 1.38- and 1.62-fold increases in MMP-2 activity, respectively (Fig. 5C). Similarly, synovial fibroblasts treated with 1,5 and $10 \mathrm{ng} / \mathrm{ml} \mathrm{IL-1} \beta$ for $72 \mathrm{~h}$ exhibited 1.54-, 1.86- and 2.3-fold increases in MMP-2 activity, respectively (Fig. 5C). The combined treatment of TNF- $\alpha$ and IL-1 $\beta$ (each $10 \mathrm{ng} / \mathrm{ml}$ ) also significantly increased MMP-2 activity $(\mathrm{P}<0.05)$, with a more marked increase in MMP-2 activity observed compared to that in cells treated with TNF- $\alpha$ or IL-1 $\beta$ alone (Fig. 5C).

\section{Discussion}

The current study principally observed that synovial fibroblasts participate in the healing process of injured cruciate ligaments by increasing the expression of MMPs and decreasing the expression of LOXs within the inflammatory microenvironment of damaged ligament tissue.

Previous studies have documented that the time course of inflammatory cytokine levels, including TNF- $\alpha$ and IL-1 $\beta$, observed in joint fluid surrounding acute ACL injuries is similar to that in wound fluid during ordinary wound healing processes. This suggests that the ordinary wound healing mechanism, which involves three overlapping phases of inflammation, matrix formation and remodeling, also occurs in ACL injuries $(21,25)$. Thus, disruption in any phase of the healing sequence may result in a non-healing wound.

Wound healing is a complex process dependent on reactions and interactions between distinct tissues, cells and mediators (26). A number of these mediators are necessary, particularly TNF- $\alpha$ and IL- $1 \beta$, which are secreted by resident fibroblasts and inflammatory cells (including macrophages and monocytes) (27). Although TNF- $\alpha$ and IL-1 $\beta$ are structurally unrelated and bind to distinct receptors, they operate in a similar biological manner and commonly work synergistically (28). The cytokines influence a number of processes at wound sites, including fibroblast proliferation, chemotaxis, synthesis and breakdown of ECM proteins, and regulation of the immune response (29). However, excessive amounts of inflammatory cytokines may have a negative effect on wound healing, with previous results in animal models indicating differing roles of cytokines depending on dosage $(30,31)$.

Following cruciate ligament injury, increased levels of TNF- $\alpha$ in synovial fluid may stimulate synovial fibroblasts to produce IL-1, with IL-1 itself increasing TNF- $\alpha$ activity (32). In addition, TNF- $\alpha$ and IL-1 may stimulate the production of IL-6 from synovial fibroblasts and chondrocytes, which in turn promotes the immune response by stimulating lymphocyte differentiation $(33,34)$. Mutual promotion among proinflammatory factors may also increase levels of the factors in synovial fluids. Furthermore, the knee joint cavity 


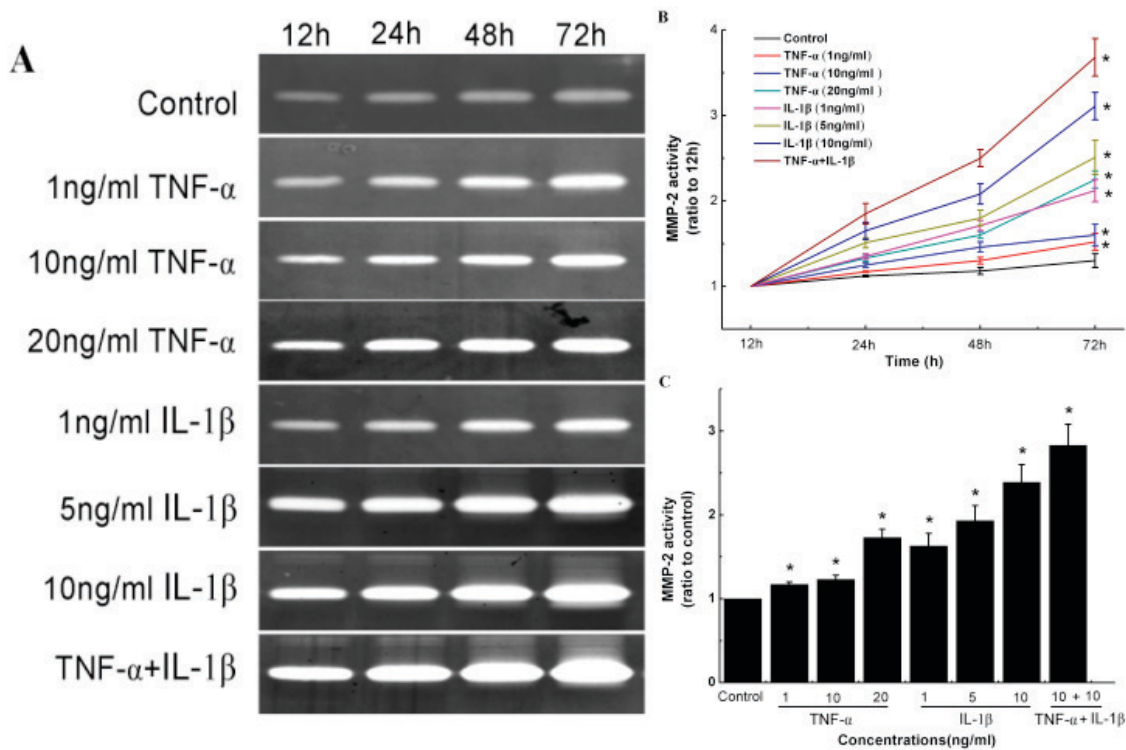

Figure 5. Effects of TNF- $\alpha$, IL-1 $\beta$ and both cytokines together on MMP-2 activity in human knee synovial fibroblasts. (A) Zymographic analysis of conditioned media from synovial fibroblasts treated with TNF- $\alpha(1,10$ and $20 \mathrm{ng} / \mathrm{ml})$ and IL-1 $\beta(1,5$ and $10 \mathrm{ng} / \mathrm{ml})$ for 12, 24,48 and $72 \mathrm{~h}$. The gels shown are representative of four independent experiments. (B) Change in MMP-2 activity over the investigated time period. (C) Quantitative data corresponding to measurements at $72 \mathrm{~h}$ post-cytokine treatment. Data are presented as the mean \pm standard deviation, $\mathrm{n}=4$. ${ }^{*} \mathrm{P}<0.05$ vs. untreated control cells. TNF- $\alpha$, tumor necrosis factor- $\alpha$; IL-1 $\beta$, interleukin-1 $\beta$; MMP-2, matrix metalloproteinase-2.

is a relatively isolated fluid-filled space enclosed by synovial membrane, which facilitates the accumulation of inflammatory cytokines in synovial fluid. High concentrations of inflammatory cytokines in synovial fluid may inhibit ACL healing by a number of mechanisms, including inhibition of ACL fibroblast migration (35), suppression of type I collagen synthesis (36) and stimulation of ACL fibroblast apoptosis (37). It has previously been demonstrated that the impaired healing ability of the ACL is associated with a high level of expression and/or activation of MMPs in ACL fibroblasts induced by inflammatory cytokines (38). Wang et al (19) and previous studies by our group $(20,39)$ have also indicated that synovial fibroblasts are sensitive to TNF- $\alpha$, due to its regulatory effects on the production and activity of MMPs and LOXs. These data suggest that synovial fibroblasts serve a key role in the regulation of the joint cavity microenvironment.

The current study demonstrated that TNF- $\alpha$, IL-1 $\beta$ and a combination of both cytokines upregulated the expression of MMP-1, -2 and -3 in synovial fibroblasts. In addition, a combination of the inflammatory cytokines exhibited synergistic effects in the induction of MMP-2 expression. Gelatin zymography also indicated that TNF- $\alpha$ and IL- $1 \beta$ together increased the production and activity of MMP- 2 in synovial fibroblasts in a dose- and time-dependent manner, although IL- $1 \beta$ was more efficient at this than TNF- $\alpha$. Pro-MMP-2 is visible at $\sim 72 \mathrm{kDa}$ and active MMP-2 is visible at $\sim 62 \mathrm{kDa}$. These two forms carry out the same enzymatic reaction, however pro-MMP-2 has $\sim 10 \%$ the activity of active MMP-2 (9). It was observed that a combination of TNF- $\alpha$ and IL- $1 \beta$ enhanced MMP- 2 activity to a greater extent than TNF- $\alpha$ and IL- $1 \beta$ alone. These results suggest that the release of MMPs from synovial fibroblasts is sensitive to inflammatory cytokines, and that TNF- $\alpha$ and IL-1 $\beta$ are involved in the healing process of knee joint tissues. In addition, findings that TNF- $\alpha$ and IL- $1 \beta$ may directly stimulate the synthesis of MMP-1, -2 and -3 in synovial cells are similar to those of previous studies on a number of other cells types, including tendon fibroblasts (40), periodontal ligament cells $(41,42)$, chondrocytes $(43,44)$, vascular smooth muscle cells (45) and gingival fibroblasts (46).

Increased levels of MMPs in synovial fibroblasts, induced by TNF- $\alpha$ and IL-1 $\beta$, may be secreted into synovial fluid, where they potentially activate other members of the MMP family. A previous study has demonstrated that MMP-1 activates latent MMP-2, MMP-2 activates latent MMP-13 and MMP-3 activates latent MMP-1, 9 and 13 (47). Therefore, the mutual activation of MMPs creates a complex network of proteases in the synovial fluids. In addition, it has been previously documented that MMPs are inflammatory cytokine-converting enzymes, with findings that TNF- $\alpha$ and IL-1 $\beta$ may be proteolytically activated by different MMPs, including MMP-2, -3, -7, -9, -12, -14 and -17 (48). Thus, the formation of a positive feedback loop may increase the level of MMPs and inflammatory cytokines within the sealed joint cavity. In turn, high levels of MMP expression and activity within the joint fluid may impede ACL healing by altering the balance between the degradative and biosynthetic arms of the ligament tissue remodeling process.

LOX staining surrounding areas of inflammation has been documented in immunohistochemical studies in a number of pathologies, including gingival hyperplasia and liver fibrosis, suggesting that the expression of LOXs may also be regulated by inflammatory factors, such as TNF- $\alpha$ and IL-1 $\beta(49,50)$. Similar to the effects of TNF- $\alpha$, the current study observed that IL-1 $\beta$ downregulated LOXL-2 and -4 expression in synovial fibroblasts. By contrast, IL-1 $\beta$ also upregulated LOX, LOXL-1 and -3 expression. The ability of IL- $1 \beta$ to promote the expression of LOXs in synovial cells also exists in other cell types, including human lung (51) and adult skin fibroblasts (52). When TNF- $\alpha$ and IL-1 $\beta$ cytokines were combined, the expression of LOXs was downregulated to below that in 
control cells. In synovial fluid, this inhibitory effect of TNF- $\alpha$ and IL-1 $\beta$ may decrease the concentration of LOXs in synovial fluid and result in a reduced degree of cross-linking between ECM proteins, thus weakening the mechanical properties of ECM and increasing its susceptibility to degradation by MMPs. These effects would again alter the balance between the degradative and biosynthetic arms of the ligament remodeling process and offer an additional explanation for the poor healing ability of cruciate ligaments.

A limitation of the current study is that ACL injury was only partially mimicked. This does not represent an in vivo situation, in which levels of IL-1 $\alpha$ TGF- $\beta$ and other cytokines are elevated in knee joint fluid following cruciate ligament injury. This effect may additionally modulate the levels of LOXs and MMP-1,2 and 3 produced by synovial cells and other intra-articular tissues. Thus, studies investigating the effects of a global cytokine profile on ACL injury are warranted.

In conclusion, the present study observed that TNF- $\alpha$ and IL-1 $\beta$ synergistically regulate the expression of the majority of LOXs and MMPs investigated, and the activity of MMP-2, in synovial fibroblasts. This indicates that the synovium is sensitive to inflammatory factors and serves a key regulatory role in the knee joint cavity microenvironment during the healing process. These findings may aid in the development of therapeutic methods for the replacement and/or regeneration of ligament tissue in patients with cruciate ligament trauma.

\section{Acknowledgements}

The current study was supported by the National Natural Science Foundation of China (grant no. 11702093), the General Project of Hunan Provincial Education Department (grant no. 14C0452), the Natural Science Foundation of Hunan Province (grant no. 2015JJ6042), the Innovation and Attracting Talents Program for Colleges and Universities, China (grant no. B06023) and the National Institutes of Health, USA (grant no. AR45635).

\section{References}

1. Woo SL, Abramowitch SD, Kilger R and Liang R: Biomechanics of knee ligaments: Injury, healing, and repair. J Biomech 39: $1-20,2006$.

2. Hill CL, Seo GS, Gale D, Totterman S, Gale ME and Felson DT: Cruciate ligament integrity in osteoarthritis of the knee. Arthritis Rheum 52: 794-799, 2005.

3. Sun K, Zhang J, Wang Y, Xia C, Zhang C, Yu T and Tian S: Arthroscopic reconstruction of the anterior cruciate ligament with hamstring tendon autograft and fresh-frozen allograft: A prospective, randomized controlled study. Am J Sports Med 39: 1430-1438, 2011.

4. Kim HS, Seon JK and Jo AR: Current trends in anterior cruciate ligament reconstruction. Knee Surg Relat Res 25: 165-173, 2013.

5. Bray RC, Leonard CA and Salo PT: Correlation of healing capacity with vascular response in the anterior cruciate and medial collateral ligaments of the rabbit. J Orthop Res 21 $1118-1123,2003$.

6. Nagineni CN, Amiel D, Green MH, Berchuck $M$ and Akeson WH: Characterization of the intrinsic properties of the anterior cruciate and medial collateral ligament cells: An in vitro cell culture study. J Orthop Res 10: 465-475, 1992.

7. Sung KL, Yang L, Whittemore DE, Shi Y, Jin G, Hsieh AH, Akeson WH and Sung LA: The differential adhesion forces of anterior cruciate and medial collateral ligament fibroblasts: Effects of tropomodulin, talin, vinculin, and alpha-actinin. Proc Nati Acad Sci USA 93: 9182-9187, 1996.
8. Wiig ME, Amiel D, Ivarsson M, Naqineni CN, Wallace CD and Arfors KE: Type I procollagen gene expression in normal and early healing of the medial collateral and anterior cruciate ligaments in rabbits: An in situ hybridization study. J Orthop Res 9: 374-382, 1991.

9. Zhou D, Lee HS, Villarreal F, Teng A, Lu E, Reynolds S, Qin C, Smith J and Sung KL: Differential MMP-2 activity of ligament cells under mechanical stretch injury: An in vitro study on human ACL and MCL fibroblasts. J Orthop Res 23: 949-957, 2005.

10. Chithra P, Sajithlal GB and Chandrakasan G: Influence of Aloe vera on collagen characteristics in healing dermal wounds in rats. Mol Cell Biochem 181: 71-76, 1998.

11. Garqiulo S, Gamba P, Poli G and Leonarduzzi G: Metalloproteinases and metalloproteinase inhibitors in age-related diseases. Curr Pharm Des 20: 2993-3018, 2014.

12. Fan SH, Wang YY, Lu J, Zheng YL, Wu DM, Zhang ZF, Shan Q, Hu B, Li MQ and Cheng W: CERS2 suppresses tumor cell invasion and is associated with decreased V-ATPase and MMP-2/MMP-9 activities in breast cancer. J Cell Biochem 116: 502-513, 2015.

13. Vater CA, Harris ED Jr and Siegel RC: Native cross-links in collagen fibrils induce resistance to human synovial collagenase. Biochem J 181: 639-645, 1979.

14. Avery NC and Bailey AJ: Enzymic and non-enzymic cross-linking mechanisms in relation to turnover of collagen: Relevance to aging and exercise. Scand J Med Sci Sports 15: 231-240, 2005.

15. Wang Y, Tang Z, Xue R, Singh GK, Lv Y, Shi K, Cai K, Deng L and Yang L: TGF- $\beta 1$ promoted MMP- 2 mediated wound healing of anterior cruciate ligament fibroblasts through NF- $\kappa \mathrm{B}$. Connect Tissue Res 52: 218-225, 2011.

16. Xie J, Jiang J, Huang W, Zhang Y, Xu C, Wang C, Yin L, Chen PC and Sung KL: TNF- $\alpha$ induced down-regulation of lysyl oxidase family in anterior cruciate ligament and medial collateral ligament fibroblasts. Knee 21: 47-53, 2014.

17. Tang Z, Yang L, Xue R, Zhang J, Wang Y, Chen PC and Sung KL: Differential expression of matrix metalloproteinases and tissue inhibitors of metalloproteinases in anterior cruciate ligament and medial collateral ligament fibroblasts after a mechanical injury: Involvement of the p65 subunit of NF-kappaB. Wound Repair Regen 17: 709-716, 2009.

18. Tang Z, Yang L, Wang Y, Xue R, Zhang J, Huang W, Chen PC and Sung KL: Contributions of different intraarticular tissues to the acute phase elevation of synovial fluid MMP-2 following rat ACL rupture. J Orthop Res 27: 243-248, 2009.

19. Wang Y, Yang L, Zhang J, Xue R, Tang Z, Huang W, Jiang D, Tang X, Chen P and Sung KL: Differential MMP-2 activity induced by mechanical compression and inflammatory factors in human synoviocytes. Mol Cell Biomech 7: 105-114, 2010.

20. Zhang Y, Huang W, Jiang J, Xie J, Xu C, Wang C, Yin L, Yang L, Zhou K, Chen P and Sung KP: Influence of TNF- $\alpha$ and biomechanical stress on matrix metalloproteinases and lysyl oxidases expressions in human knee synovial fibroblasts. Knee Surg Sports Traumatol Arthrosc 22: 1997-2006, 2014.

21. Irie $\mathrm{K}$, Uchiyama $\mathrm{E}$ and Iwaso $\mathrm{H}$ : Intraarticular inflammatory cytokines in acute anterior cruciate ligament injured knee. Knee 10: 93-96, 2003.

22. Behm B, Babilas P, Landthaler M and Schreml S: Cytokines, chemokines and growth factors in wound healing. J Acad Dermatol Venereol 26: 812-820, 2012

23. Xie J, Wang C, Yin L, Xu C, Zhang Y and Sung KL: Interleukin-1 beta influences on lysyl oxidases and matrix metalloproteinases profile of injured anterior cruciate ligament and medial collateral ligament fibroblasts. Int Orthop 37: 495-505, 2013.

24. Livak KJ and Schmittgen TD: Analysis of relative gene expression data using real-time quantitative PCR and the 2(-Delta Delta C(T)) method. Methods 25: 402-408, 2001.

25. Sinno H and Prakash S: Complements and the wound healing cascade: An updated review. Plast Surg Int 2013: 146764, 2013.

26. Barrientos S, Brem H, Stojadinovic O and Tomic-Canic M: Clinical application of growth factors and cytokines in wound healing. Wound Repair Regen 22: 569-578, 2014.

27. Migita K, Eguchi K, Kawabe Y, Ichinose Y, Tsukada T, Aoyagi T, Nakamura $\mathrm{H}$ and Nagataki S: TNF-alpha-mediated expression of membrane-type matrix metalloproteinase in rheumatoid synovial fibroblasts. Immunology 89: 553-557, 1996.

28. Soller JT, Murua-Escobar H, Willenbrock S, Janssen M, Eberle N, Bullerdiek J and Nolte I: Comparison of the human and canine cytokines IL-1(alpha/beta) and TNF-alpha to orthologous other mammalians. J Hered 98: 485-490, 2007. 
29. Shona MI, Shaun G and David MT: Differential regulation of metalloproteinase production, proliferation and chemotaxis of human lung fibroblasts by PDGF, interleukin-1beta and TNF-alpha. Mediators Inflamm 9: 155-160, 2000.

30. Guirao X and Lowry SF: Biologic control of injury and inflammation: Much more than too little or too late. World J Surg 20: 437-446, 1996.

31. Menke NB, Ward KR, Witten TM, Bonchev DG and Diegelmann RF: Impaired wound healing. Clin Dermatol 25: 19-25, 2007.

32. Di Giovine FS, Nuki G and Duff GW: Tumour necrosis factor in synovial exudates. Ann Rheum Dis 47: 768-772, 1988.

33. Cameron ML, Fu FH, Paessler HH, Schneider M and Evans $\mathrm{CH}$ : Synovial fluid cytokine concentrations as possible prognostic indicators in the ACL-deficient knee. Knee Surg Sports Traumatol Arthrosc 2: 38-44, 1994.

34. Choi HM, Oh DH, Bang JS, Yang HI, Yoo MC and Kim KS: Differential effect of IL-1 $\beta$ and TNF $\alpha$ on the production of IL-6, IL-8 and PGE2 in fibroblast-like synoviocytes and THP-1 macrophages. Rheumatol Int 30: 1025-1033, 2010.

35. Witkowski J, Yang L, Wood DJ and Sung KL: Migration and healing of ligament cells under inflammatory conditions. J Orthop Res 15: 269-277, 1997.

36. Greenwel P, Tanaka S, Penkov D, Zhang W, Olive M, Moll J, Vinson C, Di Liberto M and Ramirez F: Tumor necrosis factor alpha inhibits type I collagen synthesis through repressive CCAAT/enhancer-binding proteins. Mol Cell Biol 20: 912-918, 2000.

37. Murakami H, Shinomiya N, Kikuchi T, Yoshihara Y and Nemoto K: Upregulated expression of inducible nitric oxide synthase plays a key role in early apoptosis after anterior cruciate ligament injury. J Orthop Res 24: 1521-1534, 2006.

38. Wang Y, Tang Z, Xue R, Singh GK, Shi K, Lv Y and Yang L: Combined effects of TNF- $\alpha$, IL-1 $\beta$, and HIF-1 $\alpha$ on MMP-2 production in ACL fibroblasts under mechanical stretch: An in vitro study. J Orthop Res 29: 1008-1014, 2011.

39. Fu C, Xie J, Chen R, Wang C, Xu C, Chen C, Wang Z, Lin L, Huang W, Liang X and Sung KL: Effect of titanium particles and TNF-alpha on the gene expression and activity of MMP-1, 2, 3 in human knee joint synovial cells. Sheng Wu Yi Xue Gong Cheng Xue Za Zhi 30: 1022-1026, 2013 (In Chinese).

40. Schulze-Tanzil G, Al-Sadi O, Wiegand E, Ertel W, Busch C, Kohl B and Pufe T: The role of pro-inflammatory and immunoregulatory cytokines in tendon healing and rupture: New insights. Scand J Med Sci Sports 21: 337-351, 2011.

41. Nakaya H, Oates TW, Hoang AM, Kamoi K and Cochran DL: Effects of interleukin-lbeta on matrix metalloproteinase-3 levels in human periodontal ligament cells. J Periodontol 68: 517-523, 1997.
42. Ahn SJ, Rhim EM, Kim JY, Kim KH, Lee HW, Kim EC and Park SH: Tumor necrosis factor- $\alpha$ induces matrix metalloproteinases-3, -10 and -13 in human periodontal ligament cells. J Periodontol 85: 490-497, 2014

43. Raymond L, Eck S, Hays E, Tomek I, Kantor S and Vincenti M RelA is required for IL-1beta stimulation of matrix metalloproteinase-1 expression in chondrocytes. Osteoarthritis Cartilage 15 431-441, 2007.

44. Dunn SL, Wilkinson JM, Crawford A, Le Maitre CL and Bunning RA: Cannabinoid WIN-55,212-2 mesylate inhibits interleukin-1 $\beta$ induced matrix metalloproteinase and tissue inhibitor of matrix metalloproteinase expression in human chondrocytes. Osteoarthritis Cartilage 22: 133-144, 2014.

45. Zhong Y, Yu W, Feng J, Fan J and Li J: Curcumin suppresses tumor necrosis factor- $\alpha$-induced matrix metalloproteinase-2 expression and activity in rat vascular smooth muscle cells via the NF- $\kappa$ B pathway. Exp Ther Med 7: 1653-1658, 2014.

46. Gotoh K, Nemoto E, Kanaya S and Shimauchi H: Extracellular $\beta-\mathrm{NAD}(+)$ inhibits interleukin-1-induced matrix metalloproteinase- 1 and -3 expression on human gingival fibroblasts. Connect Tissue Res 54: 204-209, 2013.

47. Kerrigan JJ, Mansell JP and Sandy JR: Matrix turnover J Orthod 27: 227-233, 2000

48. Rodríguez D, Morrison C and Overall CM: Matrix metalloproteinases: What do they not do? New substrates and biological roles identified by murine models and proteomics. Biochim Biophys Acta 1803: 39-54, 2010.

49. Trackman PC, Graham RJ, Bittner HK, Carnes DL, Gilles JA and Graves DT: Inflammation-associated lysyl oxidase protein expression in vivo, and modulation by FGF-2 plus IGF-1. Histochem Cell Biol 110: 9-14, 1998.

50. Desmoulière A, Darby I, Costa AM, Raccurt M, Tuchweber B, Sommer P and Gabbiani G: Extracellular matrix deposition, lysyl oxidase expression, and myofibroblastic differentiation during the initial stages of cholestatic fibrosis in the rat. Lab Invest 76 : 765-778, 1997.

51. Roy R, Polgar P, Wang Y, Goldstein RH, Taylor L and Kagan HM: Regulation of lysyl oxidase and cyclooxygenase expression in human lung fibroblast: Interaction among TGF-beta, IL-1 beta, and prostaglandin E. J Cell Biochem 62: 411-417, 1996.

52. Cenizo V, André V, Reymermier C, Sommer P, Damour O and Perrier E: LOXL as a target to increase the elastin content in adult skin: A dill extract induces the LOXL gene expression. Exp Dermatol 15: 574-581, 2006. 